\title{
Analysis on Health Care Function of Horticultural Therapy
}

\author{
Yulin Liu, Jianjun Liao \\ Department of Urban Construction, \\ University of South China, \\ Hengyang, 421000, China
}

\begin{abstract}
Horticulture Therapy, a new approach to health care, which can relieve stress and rehabilitate mind by touching and feeling gardening materials. Through researches on current society, we find that it is necessary to carry out horticultural therapy in our county. The Article has analyzed health effects of Horticultural therapy from the two aspects:1.effect of sense.2motion experience, and put forward some suggestions about design ideas of horticultural therapy garden .
\end{abstract}

Keywords-horticulture therapy; health care; suggestion of design.

Currently, rapidly expanding city, highly-dense buildings, busy city traffic, are all reflect that the people's living standards have been rising, but at the same time, the pressure from all sides has been increased. Studies have shown that more and more people are impacted by mental depression and Sub-health state., Meanwhile, social and family issues are serious, due to many problems resulting from the fast pace of our soceity such as weak social foundation ,loss of values, the increase of juvenile delinquency. Horticultural therapy is an effective way to solve this problem[i].As early as 1699, Lee - Mecca in "British garden" said: In spare time, you might dig , quietly sit, pull weeding, in the garden. it is a good way to maintain physical and mental health.[ii]

1792, a psychiatric hospital, York shelters, was committed to using natural forces as a therapeutic treatment, they also introduced the way of playing with rabbits and chickens for patients[ iii ]. In Early 19th century, a psychiatrist form north of Scotland make a patient labor in their own farm, which greatly improved the effect of treatment; in the middle of the 9th century ,some mental hospital alleviated or completely cured the Patient's condition by planting flowers and trees.

\section{HoRTiCUltURE THERAPY}

Horticulture Therapy is defined by American Horticultural Therapy Association (AHTA)as follows: Horticultural therapy ,the use of plant cultivation and horticulture operating activities,is hope to update people's condition from social, educational, psychological and other aspects [iv].Back in ancient China, gardening craftsmen have recognized that horticultural activities can make people "keep within the spirit", "tranquil nothingness[v]."

\section{HEATH EFFECT OF HORTICULTURE THERAPY}

\section{A. Effect of Sense}

Plant is the main material of Horticultural therapy[vi] . Horticultural therapy can offer different stimulation for people, including vision, hearing, taste, touch and smell and so on. For example, fragrance emitted by flowers and plants can stimulate smell , and vision can be stimulated by plants which exhibit different shape and color in four seasons, and hearing by the sound of water, tweetie, the voice of the tree swing and so on .

1) Smell experience

Studies have shown that the gaseous aromatic hydrocarbon released by plants has strong capacity of disinfection as well as infiltration against human skin. Thus when it is absorbed by human skin or mucosa, it can appropriately stimulate the generation of immune protein and untense the nervous system ,finally enhancing the body's resistance[vii]. Recently, the report indicate that Rose oil can relieve oxidative toxicity in brain caused by depression[viii].and The amount of post-operative opioid analgesics can be reduced by the use of lavender aromatherapy.

Plant resources are rich in our country and more than 70 families from 600 to over 800 kinds have been found[ix]. Flowers and plants can emit different kinds of smell, which can arrive to cerebral center through Meatus nerve to improve the function of the brain and stimulate the generation of pleasure. It has been proved by modern science that molecular size in the potpourri not only have effect of sterilization but also can purify environment, A test has shown that when staying in beautiful flowers and tree, people's skin temperature lowers $1{ }^{\circ} \mathrm{C}-2{ }^{\circ} \mathrm{C}$ and their pulse reduces 4-8 times per minute on average, AS a result ,the breathing was became slow and even ,and sensitivity of hearing and thinking also be enhanced[x]. Lilac blooms in Spring not only have strong ability of air purification, but also sedation.

2) Vision experience

Visual stimulation is good for our health by the appreciation of plant color and shape. Brightness and warmness is the feature of warm colors, making people happy and cheerful, while quietness is the characteristics of cold color, which making people fall into sense of detachment. Red, orange, yellow, are warm color, which are so beautiful that can make the heart beat faster. green, 
blue, purple belong to Cool colors and deepness is the feature of them , making people feel calm and relaxed.

\section{3) Hearing experience}

Studies have shown that listening the beautiful sound that you subjectively regard as comfortable, can make the brain calm down and let the body stay in a relaxed manner[xi]. Auditory sense belong to the human sensory system. Plant with different sizes, and shapes can make all kinds of wonderful sounds in wind and rain, some are mild,and some are powerful.. Sounds come from nature can relieve people's stress and reduce the Uneasy mood.

4) Health effects of taste experience

A corner in garden can be designed as a taste garden, specially for planting fruits, vegetables, and herbs. Those easily planted fruits and vegetables when they are mature can be cooked and eaten together. adding edible herbs or brewing scented tea can produce the effect of treatment of taste. In addition, the planting Should avoid the use of pesticides, just for preventing the accident when the participants touch and eat. In the community or residential green garden, some edible plants or fruit trees are good choices. The selection of suitable trees, and the management of the planting can achieve good results. many fruit trees can be planted in the attached green space of some units. When the fruits are ripe, the share of the fruit and the joy of harvest arouse fabulous childhood memories.

\section{5) Tactile experience}

The sense of touch is very direct and can influence someone deeply and will stimulate the intuition area and motor area in the cerebral cortex [xii].By allowing participants to touch different plants ,to feel the sense of stereo and to understand the nature of the material, a sensory stimulation effect can be helped to form . Different parts of plants such as barks, leaves, flowers, fruits, seeds, can provide different sensory stimulation; the different textures of different plants, smooth or rough, hairy or solid, crisp or fleshy, will have different tactile stimulation too.

\section{B) Motion experience}

1) Physical activity, strengthening the vitality

Horticulture is a very effective method of health care[xiii], the participants according to their actual situation can participate in the horticulture. Besides, different ages and physical strength users, through various horticulture operations (plant repairs, seeding, fertilization), and other operations, not only can reach the effect of exercise, but also a uniquely elegant feel,. With time, participants will be able to gradually enhance the physical condition in Horticulture process, achieveing the purpose of health care.

2) The ability of concentation

For Disabled, and health groups easy to cause mental, physical aging, but horticultural activities is one of the best measures to prevent aging. People of different ages in horticultural activities can promote focus attention and mobilize the human brain mind, enhance their perception and understanding for the common things in daily lives Savor rules of life from tiny event, build self-confidence and a sense of accomplishment in their activities and form meaningful life attitude to guid a new life .

3) Interaction, eliminate haze

As the saying goes "the older the more sentimental." Elderly desire the care from their families interacting with others, but "no longer work due to older people busy, rest increased, but also enable them to bring a series of changes in the mental emotional, prone to depression and loss. In horticulture process, participants learn through mutual exchange of skills and knowledge of horticulture, resonate, and promote exchanges interact, meet new friends, which swept away the hearts of lonely. if a family of three (father, mother, child), through the practice of horticultural activities undoubtedly increase the affection of family members can make a more harmonious family, enhance happiness, while the parents who to set an example approach, educating the next generation"No pain no gain," the life lessons, with far-reaching. young couple mutually interaction horticulture, horticultural activities adds a more romantic and innocence.

\section{Design Suggestions ABOut Horticulture THERAPY}

\section{A. The embodiment of the cross subject}

The current Gardening health garden design boundaries between the various disciplines is still very obvious, not much contact interludes, have less comprehensive research appears. In the design if the medicine, sociology, psychology, gardening, aesthetics and other disciplines can organic integration, at the same time reflected in the various elements of the mind in the garden, will make the garden users feel more comfortable, safe, and also provides the researchers new research idea.

\section{B. Emphasis on mental health effects reflect}

In the current society, because of the increasing pressure on people's life, prone to negative emotions and pessimistic thoughts, if in the long term, easy to suffer from mental illness such as depression and anxiety. Therefore, the landscape design should pay attention to plant in visual experience, physiological health effect. At the same time, both psychological spiritual breakthrough design, add more diverse human element makes the participants feel love and hope. For example, write inspirational or warm slogan in the conspicuous position, give a person the feeling of optimism.

\section{Emotional design of humanization}

Accumulation of negative human emotions, the human body organ has pathological effects of deep-seated. "Hate, anger, resentment, anger, annoyance" called the person's mood ruling. Biologists believe that emotions have effects on the brain nervous system, endocrine system, which can lead to cardiovascular, digestive, immune system a series of changes. Long-term accumulation of negative emotions , sentiment on the human body, has a direct impact to the human body like "heart, liver, spleen, lung, kidney” . 


\section{CONCLUSIONS}

Horticultural therapy is a new type of science, which is very late start in our country, but ,there is no doubt that it has benefit to people's health .Garden plants is good for people's health through stimulus people's "five senses" .in addition, people take part in gardening activities also have other effect include ,stretched limbs, concentration, Neutralize you emotions, which is take important part in personal effect on physical, mental, emotion. horticulture therapy is promising in China.

\section{REFERENCES}

[1] Meyer H A, Recknagel A B, Stevenson D D, et al. Forest Management (2nded) [M]. New York: Ronald Press Company,1961.

[2] Shuhua Li. international popular Horticultural therapy [J]Landscape, 2004,(10)

[3] Clare Bloom field MCSP. Horticultural therapy and the older adult population[J]. Physiotherapy,1998,84(12):626.

[4] Shuhua Li. Horticultural therapy must establish disciplinary system with Chinese characteristicsas soon as possible[J].Chinese garden magazine ,2000,16(3):17-19.

[5] Puming Li. Psychology and Art[M]. Yunnan: Yunnan People's Press, 1996.

[6] Claudia Kalb, Vanessa Juarez Into the wild: a Scientific approach[J].Newsweek,2005,146(25):60

[7] Proctor, Shannon. Budding futures [J ]. Charleston Magazine, 2006, 20(4): 80 -84.

[8] Hof J, Bevers M. Spatial optimization in ecological applications[M]. New York : Columbia University Press,2002.

[9] Jin Liu. Aromatic plant resources of China [J].Flower Gardening of China ,2004(10):4-5.

[10] XiuwenZhang, Yuan Zhang, analysis on Plants effect in Horticultural therapy[J] .modern garden, 2012(2)24-27

[11] Miyazaki Yoshifumi, Good effect of forest bathing[M].Tokyo:Ideal Magazine ,2003:53-84.

[12] Xiankun Kong. application of feeling principle in Landscape Design[D].Beijing Forestry University ,2001:46-49.

[13] RELF. The role of plant and horticulture in human well-being and quality of life [J]. People -plant Relationship, 2001, (1): 2 -5 